\title{
Accessing Sub-Saharan African migrant group for public health interventions, promotion, and research: the 5-wave- approach
}

\author{
Adekunle Adedeji@
}

Correspondence: mail@ade-adedeji. com; adekunle.adedeji@stud.uke. uni-hamburg.de Center for Psychosocial Medicine, Department of Medical Psychology, University Medical Center Hamburg-Eppendorf, Martinistraße 52, 20251 Hamburg, Germany

\begin{abstract}
The aim of this paper is to presents the validation of the 5-wave approach as a method capable of easing access and approximating a representative sample of a hard-to-reach population group (Sub-Saharan African migrants in Germany) for health, and social intervention projects and research.

The 5-wave-approach addresses the non-representativeness in the Sudman and Kalton snowballing sampling technique by breaking down the discriminative referral system (snowball system) into five separate components. Data on socio-demographic characteristics collected in a cross-sectional from 532 Sub Saharan African migrants in Germany were compared with data from Germany Foreign Population registry 2016 (AuslaendBevoelkerung 2016) to check for the validity and representativeness of the method.

Data comparison shows that sample socio-demographics characteristics reflect population characteristics, as presented in the 2016 German foreign population report.

This finding supports the 5-wave-approach as a method capable of capturing a sample of Sub-Saharan African migrants (SSA migrants) that reflects and represents population demographics characteristics. The practicability of this approach offers health and social worker, policymakers and researchers with a communication channel that open up access to the larger group and facilitates the delivery of more efficient intervention projects.
\end{abstract}

Keywords: Migration, Sub-Saharan African migrants, Sampling, Migrant access, Health promotion

\section{Introduction}

The Sudman and Kalton snowballing sampling method represent an alternative method for the sampling of special populations to produce useful estimates for social and health research. Generally, this method relies on single or multiple registers of persons in certain key positions to construct comprehensive sample frames that are hoped to reflects population characteristics (Sudman \& Kalton, 1986). However, since the quality of the resultant sample depends on the comprehensiveness of the sample frame, this method does not guarantee representativeness of samples and is biased

(c) The Author(s). 2019 Open Access This article is distributed under the terms of the Creative Commons Attribution 4.0 International License (http://creativecommons.org/licenses/by/4.0/), which permits unrestricted use, distribution, and reproduction in any medium, provided you give appropriate credit to the original author(s) and the source, provide a link to the Creative Commons license, and indicate if changes were made. 
towards those with many contacts with other members of the particular population. While the significance of a representative sample is long established, its implications for minority groups and hard-to-reach population group cannot be overemphasis (Petersen, Minkkinen, \& Esbensen, 2005; Representative Sample, 2008). Previous research has shown higher representativeness to reduce the influence of outliers or extreme observations and thereby, provide researchers with in-depth and more accurate insights into community features and trends that facilitate social involvement and interactions (Faugier \& Sargeant, 1997). More so, for hard-to-reach population, where researchers are in a position to collect rare data, the representativeness of such data is crucial for the development of evidence base that can be used as community template by service providers and policymakers to deliver programs and policies that reduce health and social inequities (Bonevski et al., 2014). Such data provide summarised and broad-reaching solutions that represent population need and maximise available resources.

To address the non-representativeness in the Sudman and Kalton snowballing sampling, this paper aims to present and validate the 5-wave approach as a method designed to ease access and approximate representative sample for health, and social intervention projects and research among a hard-to-reach population group Sub-Saharan African migrants in Germany.

Although the number of SSA migrants living in Germany continues to increase progressively since the last decade, researchers continue to struggle to access or engage this migrant group in social or health dialogues and interventions. While some have blamed this poor access on inefficient communication and group isolation (Puchner et al., 2018), others believe it to be consequential of the very different socio-cultural background and characteristics of migrants from this region of Africa. It is, however, agreed that the access barrier limits the ability of health- and social care systems to effectively respond to the needs of this migrants population (Scott, 2004).

\section{Sub-Saharan Africa migrants}

The region of Africa, south of the Sahara (also called Sub-Saharan Africa (SSA)) stretching from the undulating savannas south of the Sahara desert to the coastal mountains and valleys of the Cape comprises of 49 of the 54 African states and is home to about $17 \%$ of the world human population (United Nations, Department of Economic and Social Affairs, Population Division, 2015). This region characterised by the world highest population growth rate (Gabre-Madhin \& Haggblade, 2004), highly diverse social and demographic structure and rich cultural heritage are separated from the North by the vast Sahara desert. SSA is further distinguished with its socioeconomic, health and wellbeing stand in international compression (World Bank, 2013), SSA population physical characteristics, i.e., predominantly woolly hair and darker skin, and the North affinities with Middle Easterners and Southern Europeans. Sub-Saharan African countries are unified in their formation of communally oriented societies, which are rooted in family and facilitate indigenous welfare practices. These indigenous welfare practices transcend the 'informal' form of helping, to form the core of cultures and traditions and share strong community ties among the many different ethnic groups (Patel, Perold, Mohamed, \& Carapinha, 2007). 
The current migratory flow of migrants from SSA to Germany is believed to be consequential of a growing global migratory movement. However, the poor welfare state in many SSA countries, rapid population growth resulting in a relatively high working-age population and unemployment, importunate economic decline, poverty, environmental deterioration, corruption, civil wars, and political instability, has further intensified the flow of migrants from this region (IOM, 2013). Having doubled since 2009 and increased by $79 \%$ between $2015(269,616)$ and $2016(339,287)$, the number of migrants from SSA in Germany continue to rise progressively accounting for a small but growing share (4\%) of the 8.9 million Germany's immigrant population (Statistisches Bundesamt (Destatis), 2017). The increase in this group population has, however, not correspond to easier access for researchers and public health official. The struggle for access has further intensified; highlighted by a large number of undocumented SSA migrants', very limited knowledge of the population characteristics and distribution, and how they integrate into their new and different physical, political and social environment (Patel, Kaseke, \& Midgley, 2012). These gaps in knowledge further emphasise the need for research to reach generalisable conclusions that support holistic, effective and efficient policies and interventions that facilitate community inclusion and reducing social and health inequalities.

\section{Distinguishing features of SSA migrants}

Values, beliefs, and experiences of immigration often differ across various migrant groups. Drawing from previous research, three of the distinguishing characteristics of SSA migrants' migration experiences in Germany, that is, settlement patterns and barriers (IOM, 2013); experienced systematic and racial discrimination (Schapendonk, 2012) and patterns and formation of social networks (Deng, 1997) were identified.

\section{Settlement patterns and barriers}

While present-day boundaries of SSA countries remain a legacy of colonialism (Cohn, 2013), the effect of separating otherwise proximate political/cultural groups, or forcing traditional foes to live side by side, have created a region, disadvantaged and different in types and usage of its physical, economic, political, historical, cultural and social and welfare resources. While there is no empirical evidence on SSA migrants settlement pattern in Germany, it is however, observed that after arriving in Germany - with a mostly non-transferable training or qualification; inadequate or no knowledge of the German language; mostly-different background and understanding of social resources and structure, - many SSA migrants are faced with a new and unique challenge settling down in their new social, political, cultural and economic environment (IOM, 2013) where indigenous welfare practices are largely ignored.

\section{Victim of systematic and racial discrimination}

Recent images of SSA migrants arriving exhausted in unseaworthy boats, or hidden in fully packed cargo trucks have further reinforced a negative public perception of SSA migrants as 'desperate invaders' or 'poor victims of the ramping humanitarian crisis' among German native and in fact, other migrant groups (Schapendonk, 2012). This perception of SSA migrants often collaborates with racial attacks, labour exploitation, and discrimination in their jobs, (if structural barriers do not prevent them from 
accessing employment in the first place) to produce groups of SSA migrants, potentially disadvantaged in economic resources, social, mental and psychological well-being.

\section{Groups and network formation along the ethnic and linguistic line}

With about 3000 distinct ethnic groups and over 2000 languages, SSA is home to the most genetically and culturally diverse people on Earth. Due to the lack of universal primary means of integrating this group from over various cultural background, many SSA migrants fall back to their traditional society formation system where family, lineage, clan, tribe, and ultimately a confederation of groups with ethnic, cultural, and common linguistic characteristics, form basic units of social, economic, and political organizations and inter-communal relations (Deng, 1997). Different from other migrant groups, SSA strong ethnic alliance usually produces smaller multiple groups in the form of friendship, network or formal associations which are often closed and attracts little or no attention from the outside.

These three distinguishing features of SSA Migrants in Germany coupled with the very different cultural, linguistical, social and economic background and other migratory experience have led to the formation of smaller and isolated migrant groups segregated from the rest of Germanys native and immigrant population and hard to reach for anyone considered an outsider. These features of the SSA migrant population further magnifies the potential of sampling bias and limitations resulting from the non-representativeness of the Sudman and Kalton snowballing sampling method.

\section{Methods: the 5-wave-approach}

Sudman and Kalton (1986) exponential discriminative snowball sampling technique was elaborated and adapted to form a 5-wave-approach amid at approximating a representative sample of SSA migrants in Germany. The non-probability (non-random) sampling method (Sudman \& Kalton, 1986) has proven to be useful in collecting data when the population possesses characteristics that are rare and difficult to access (Kalton, 2001). The method involving primary data sources nominating another potential primary data sources was, therefore, elaborated in the 5 -wave-approach that attempt randomisation of the sample by breaking down the discriminative referral system into separate components in a systematic approach that increases the probability of selection for all members of the population.

Strict inclusion criterions were induced to ensure a clearly defined sample that is comparable to data from the Germany statistics office. The sample was drawn from a population of sub-Saharan Africans living in Germany that exercises all of the characteristics below:

1. Was born in one of the 49 sub-Saharan states and relocated to Germany or their children born in Germany,

2. SSA migrants who have formal residence status in Germany (i.e., holds the German citizenship or citizen of any other European Union (EU) state or has a permanent or temporary residence status, or refugee/asylum seeker status in Germany, 
3. SSA migrants who are 18 years and older - persons who have rights associated with being independent and can consent to the collection of their data,

4. He or she lives in one of the 16 Germany federal states.

Data collection was divided into five stages; that is, community leaders, community outreach, chain referrer, systematic multiplication, and natural multiplication. As presented in Fig. 1 above, these five stages are sequential in a funnel-like shape to emphasise the order in which each wave was implemented (see Fig. 1).

\section{Wave 1: community leader}

At this initial stage, community and group leaders from different organisations were invited to participate in the survey. Email and telephone invitation were sent to leaders of African students and professional associations in Germany; Ethnic and Tribal group leaders; Nongovernmental organisation, Africa Christian council, Imams, Pastors. The community leaders were extensively briefed on the aim and importance of the current survey, and how it will benefit their respective community. They were also informed of the instance incentives; 5 EUR lottery for 1 in every 5 participants.

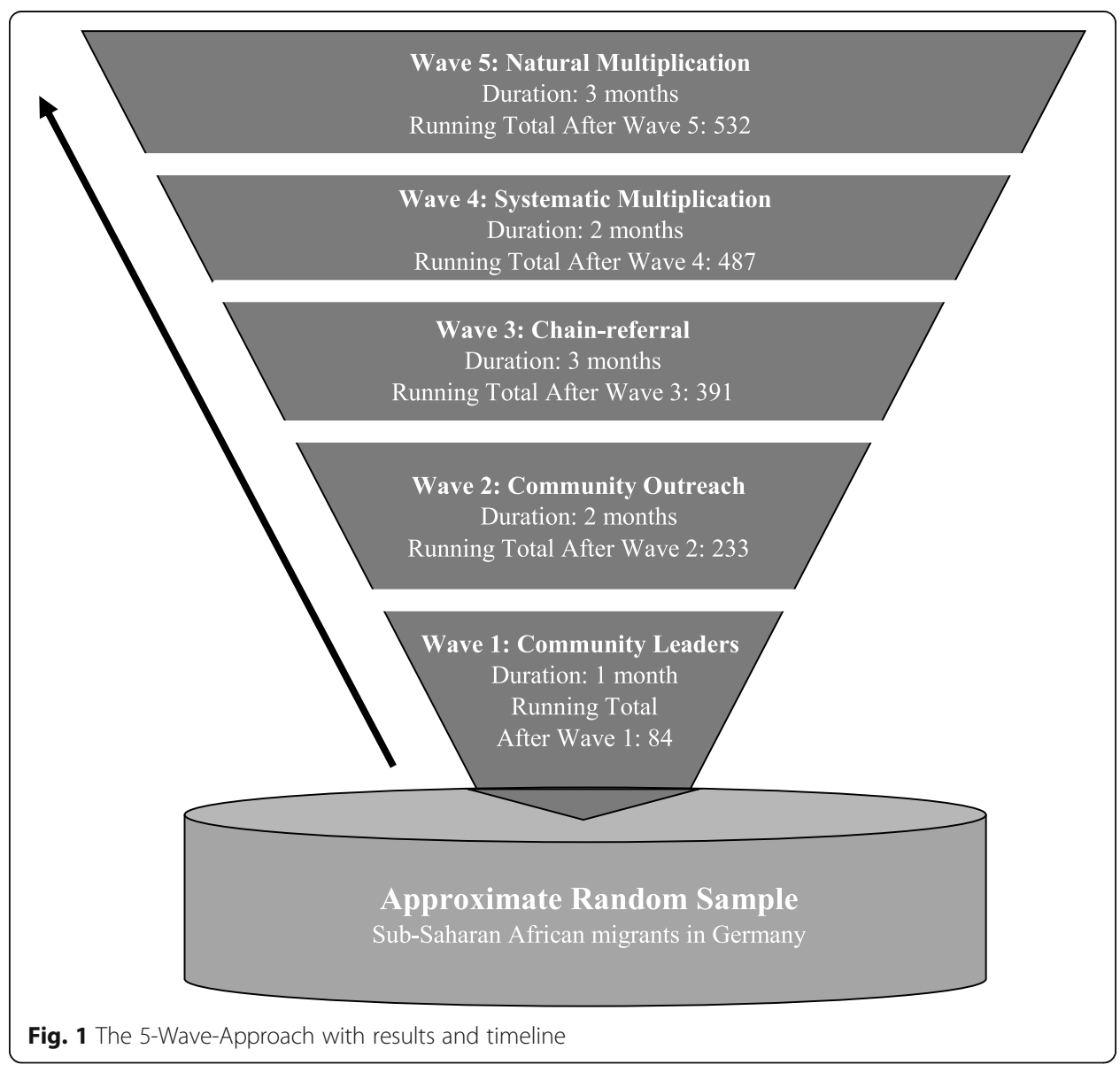


Wave 2: community outreach

Community members who met the inclusion criteria were then invited to participate in the survey. After the initial contact with various group leaders, some of the group members were already aware of the project and were willing to participate. Open invitations were sent to members of black Africans social media groups on Facebook and WhatsApp. Links to the online survey, barcode, and paper questionnaire in English, French, and German were distributed to group members. Telephone or one or one interview were presented as an alternative for those who were unable to read any of the three languages.

\section{Wave 3: chain referral}

Initial participants from wave one and two were asked to nominate, through their social and professional networks, participants who meet the eligibility criteria and can potentially contribute to our study. The nominees who responded or participated were further asked to suggest potential participants from among their acquaintances.

\section{Wave 4: systematic multiplication}

At this stage, paper questionnaire, barcode, and links to the online survey in Afro shops and beauty salons were distributed around Hamburg, Nordrhein-Westfalen, Bremen, and Berlin and posted/shared in neighbourhoods with high African migrant residence. The same was done at SSA countries missions to Germany (embassy or consulate) as well as in well known African medical practitioner offices. This systematic approach was targeted at those who might not have a social connection with African organisations or might have been excluded from previous waves.

\section{Wave 5: natural multiplication}

The last stage of the 5-wave approach involves observation without interferences from the principal researcher. At this point, no further marketing was carried out for the survey. The online platforms were left open and monitored as potential participants visit/ start or complete the online questionnaire.

\section{Data comparison}

Data on participants' socio-demographic characteristics (i.e., age, gender, state of residence in Germany, country of origin) from our survey "Social Capital and Quality of Life survey (SCQOLS) - 2017" were compared with data from Germany foreign population report 2016 (AuslaendBevoelkerung 2016) (Statistisches Bundesamt (Destatis), 2017 ) to check the representativeness of the sample and the validity of the 5-wave-approach.

\section{Germany foreign population report (GFPR) 2016 (AuslaendBevoelkerung 2016)}

This report compiled on 31 December of each year by the Federal Statistical Office is based on the foreigner central register (Ausländerzentralregisters AZR). It contains cumulative immigrants' population reported by nationality, gender, residence status, length of current stay, age and marital status. From 1995 the evaluation takes place according to the Act on the Central Register of Foreigners (AZR law) (Statistisches 
Bundesamt (Destatis), 2017). While this report is the only credible register where demographic data of SSA migrants in Germany are recorded, it only provides official documentation of demographic characteristics but lacks information on their socioeconomic performance, and other comparable life indexes.

\section{Social capital and quality of life survey (SCQOLS) - 2017}

The Germany SSA Migrants Social Capital and quality of life survey - 2017 provides unique data on Germanys' sub-Saharan African migrants' social capital, experienced quality of life, health, integration outcome, empowerment as well as an in-depth overview of groups socioeconomic, demographics and geographical characteristics.

The structured questionnaire, incorporated World Health Organization quality of life-BREF (Skevington, Lotfy, O'Connell, \& WHOQOL Group, 2004) and the World Bank integrated measure of social capital (Grootaert, Narayan, Woolcock, \& Nyhan-Jones, 2004) to collect quantitative data on overall satisfaction with health, subjective quality of life, structural and cognitive dimensions of social capital, social and political empowerment. Further questions on participants socioeconomics and demographic characteristics, i.e., age, gender, state of residence in Germany, country of origin, language skills and competencies, motivation and long-term plan for migration, household size, and characteristics were also included. The questionnaire was administrable in three languages, i.e., German, English and French and could be completed online, via paper and pencil, telephone or one-on-one. As an incentive, 5 EUR worth voucher was offered in a lottery for one in every five participants.

\section{Results}

Resulting from method complexity and overlapped nature of individual-wave-yield, only cumulative participation yields were reported at each wave. As presented below, 84 participants were recorded after wave 1; this number almost triple after the second wave (wave 2: community outreach) and added another 158 at wave 3. Further moderate increases were reported after wave 4 and five respectively (see Fig. 2).

Out of over 5000 potential participants that clicked on the online survey link or were invited to participate in the study via email or telephone, a total of 532 answered the survey questions. About $70 \%$ of the 532 participants filled out the survey questionnaire via the online platform, $18 \%$ filled out the paper and pencil questionnaire while the

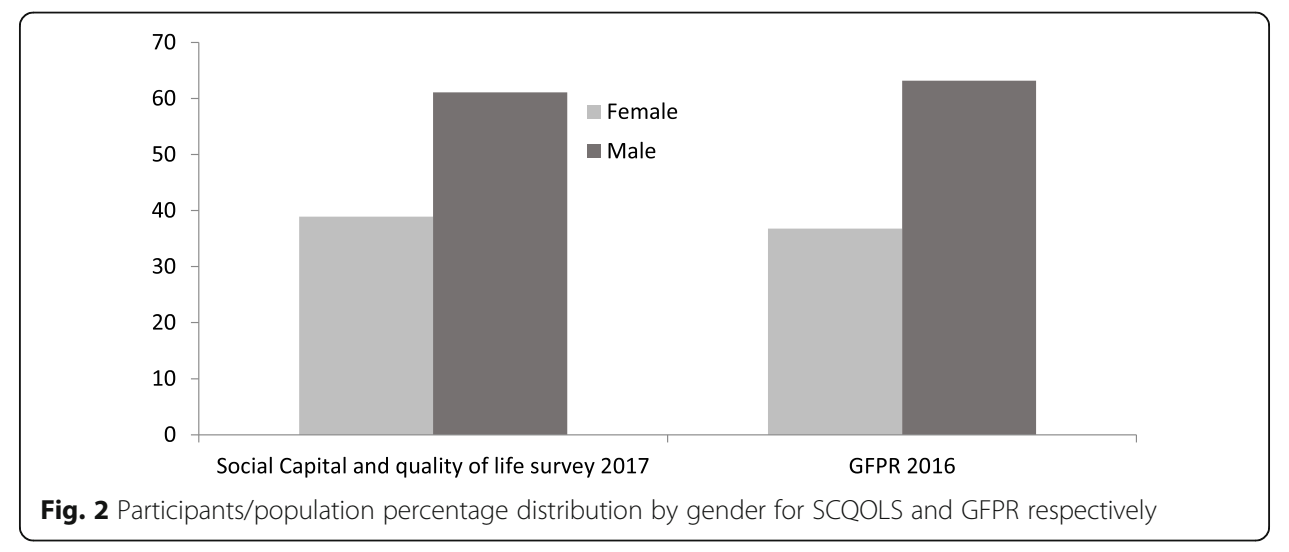


remaining $12 \%$ had questionnaire administered to them one-on-one or via telephone interview.

After an initial data check, SPSS Missing Value Analysis shows a very minimal missing data pattern. The completeness of the data is assumed to be consequential of the setup of the online questionnaire (which account for over 70\% of participants) where most questions are marked mandatory. To address reported missing data, however, 14 cases with excessive missing data and data inconsistency were removed. Furthermore, multiple data imputation was then computed to replace data missing at random (MAR). This method has been shown to produce valid statistical inference and reflects the uncertainty associated with the estimation of the missing data (Kang, 2013). To facilitate comparison of SCQOL survey participants' socio-demographic data with data from the Germany foreign population report (GFPR) 2016 (AuslaendBevoelkerung 2016) SCQOL survey participants who were born in Germany or outside of SSA or have acquired German nationality or nationality outside of SSA were excluded from this analysis. In total, data from 429 participants were then analysed and compared with data from Germany Foreign Population Report (GFPR 2016).

\section{Socio-demographics data cross-check}

Comparison of SCQOL survey participants' socio-demographic data with data from the Germany foreign population report (GFPR) 2016 (AuslaendBevoelkerung 2016) reveals a substantial similarity between both data. The compared socio-demographic characteristics are highlighted below.

\section{Gender distribution}

Both studies show an overwhelming male majority with $38.9 \%$ female participants in SCQOL survey and $36.8 \%$ in the Germany foreign population report (GFPR) respectively. While it is unexpected that the SCQOL gender distribution matches that from the GFPR, the minimal difference in the sex ratio is suspected of having resulted in the age/sex distribution of SSA migrants in Germany.

\section{Age}

Data on age shows an almost same average age of participants for both SCQOL survey (32.5 years) and GFPR 2016 (30.3 years). Both datasets project a relatively young SSA migrant's population in Germany.

\section{Marital status}

Analysis of SCQOL survey participants' marital status shows $34.3 \%$ are married while $32.9 \%$ are single, and $30.8 \%$ are in partnership but not married. That is, about one-third of study participants are in a formal matrimonial union, while more than half (63.7\%) remain unmarried, and the remaining (2\%) are either divorced or widowed. Similarly, data from GFPR shows that $23.8 \%$ of SSA migrants in Germany are married, and a vast majority (59.15) reported to be single, while $0.15 \%$ are in partnership but not married. The remaining $17.1 \%$ reported divorced (4.5\%), widowed (1\%) or unknown marital status (11.6\%). A first look at these data suggest less similar datasets (single: $\mathrm{SCQOL}=32.9 \% \mathrm{GFPR}=59.15$. In partnership but not married: $\mathrm{SCQOL}=30.8 \% \mathrm{GFPR}=$ 
0.15) however, a closer look shows similar trends with an unmarried majority (SCQOL:

63.7, GFPR: 59.3), followed by married (SCQOL: 34.3, GFPR: 23.77).

\section{SSA region of origin}

Country of origin variable in the SCQOL survey were collapsed to form a new variable - region of origin, representing West, East, Central and Southern Africa - to allow for comparison with GFPR 2016 data. In general, both surveys show a similar trend in the ranking of regions with most migrant representatives. The SCQOL data shows over half (54.2\%) of study participants are from West Africa making it the area with the highest number of SSA migrants in Germany. Similar trends were reported in the GFPR, a convincing majority (44.2\%) of the population are from West Africa. Data from other regions, i.e., East Africa (SCQOL: 21.1, GFPR: 38.8), Central Africa (SCQOL: 20.5, GFPR: 12.34) and Southern Africa (SCQOL: 4.1, GFPR: 4.8) show similar ranking patterns and trends. These results further emphasise how similar these two datasets are (Table 1).

Lastly, the state of residence data as reported in the GFPR 2016 was compared to data from SCQOL 2017. In both cases, Nordrhein-Westfalen accounts for the highest percentage of SSA migrants' (SCQOL: 18.9\%, GFPR: 23.8\%). For SCQOL data, this was followed by Hamburg (15.2\%), Bayern and Baden-Württemberg respectively while Bayern, Baden-Württemberg, and Hessen (11.8\%) held the same position for GFPR 2016. On the other hand, Thüringen with $0.5 \%$ reported the least number of participants in the SCQOL survey followed by Mecklenburg-Vorpommern and Brandenburg and Saarland with $0.69 \%$ for GFPR 2016, followed by Mecklenburg-Vorpommern and Thüringen (Fig. 3).

Table 1 Comparison of AuslaendBevoelkerung (German Foreign Population Report - GFPR) 2016 and Social Capital and quality of life survey (SCQOLS) 2017 by Sex ratio, Average age, and Family status

\begin{tabular}{lll}
\hline & SCQOLS 2017 & AuslaendBevoelkerung (GFPR) 2016 \\
\hline Percentage of female & $38.9 \%$ & $36.8 \%$ \\
Average age & 32.5 Years & 30.3 Years \\
Family Status & & \\
Single & $32.9 \%$ & $59.15 \%$ \\
Married & $34.3 \%$ & $23.77 \%$ \\
Widowed & $0.5 \%$ & $0.89 \%$ \\
Divorced & $1.6 \%$ & $4.48 \%$ \\
In partnership but not married & $30.8 \%$ & $0.15 \%$ \\
Partner diseased & - & $0.001 \%$ \\
Partnership dissolved & - & $0.01 \%$ \\
Unknown marital status & - & $11.56 \%$ \\
Region of Origin & & \\
West Africa & $49.7 \%$ & $44.22 \%$ \\
Central Africa & $17.9 \%$ & $12.34 \%$ \\
East Africa & $28.0 \%$ & $38.80 \%$ \\
Southern Africa & $4.4 \%$ & $4.75 \%$ \\
\hline Accessing Sub-Saran & &
\end{tabular}

Accessing Sub-Saharan African Migrant Group for Public Health Interventions, Promotion and Research: The 5-Wave-Approach 


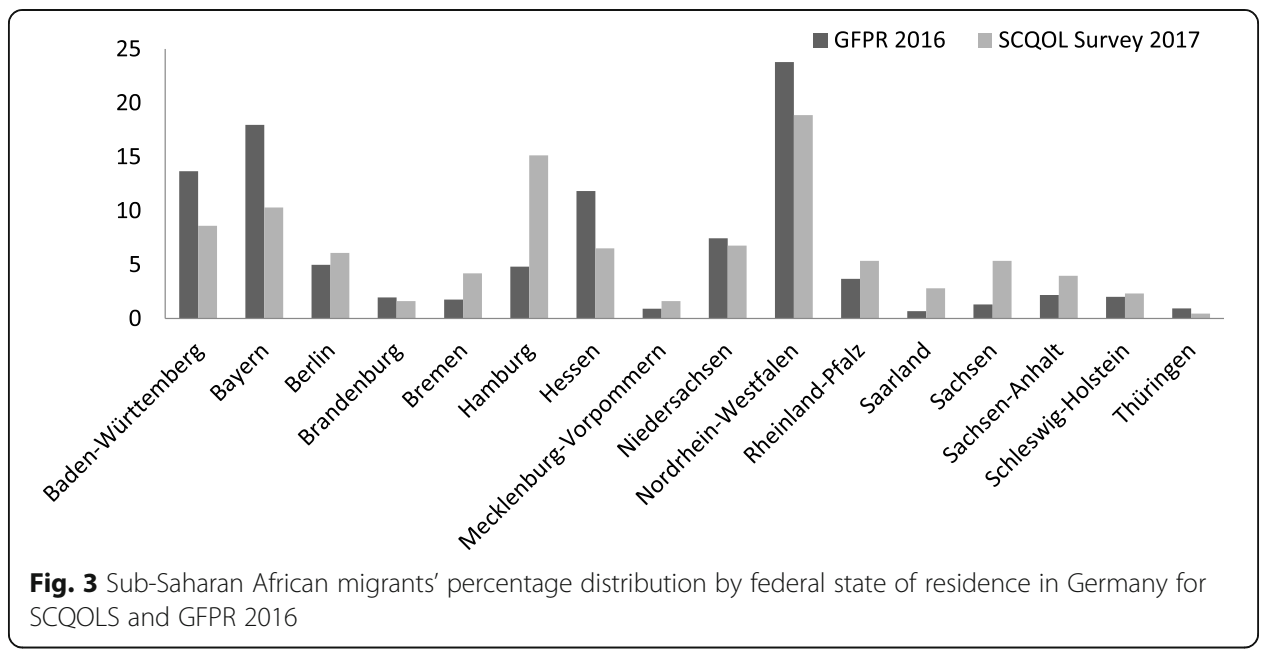

\section{Discussion}

A closer look at the result shows that the 5-wave-approach produces a sample that mirror SSA population characteristics, as presented in the 2016 German Foreign Population Report. The average age of SCQOL survey participant (32.5) reflects information available from the GFPR with about 2.2-years variation. This variation could be explained by the 18 years minimum age restriction set for participating in SCQOL survey while the GFPR data include data from all SSA migrants including children.

Similarly, both data sets show a comparable pattern in gender distribution projecting a male majority of about $61 \%$ and $63 \%$ for SCQOL and GFPR respectively. Among the many factors that shape migration, gender has often been identified as having a significant impact on migration motivation, decision and experience (Palriwala \& Uberoi, 2008). Following this trend, more SSA male has migrated to Europe due to the rigorous migration process and the SSA traditional role division that sees the man as a provider for the family (Ngubane, 2010).

The visible differences in the distribution of data on marital status are limited mainly to the categorisation of single and those in partnerships but not married. The gaps in understanding and interpreting the two terms: "single" and "in partnership but not married" in formal and social settings is believed to have contributed to the highlighted differences. Since the GFPR is an official government report (contrary to the SCQOL survey which was a social survey) respondents who are not in a formal matrimonial union are believed to be more likely to report a single marital status (Weaver, 2000) even when in an unmarried relationship. Recategorising the data into married, not married, divorced, or windowed shows overwhelming similarities in marital status distribution for both datasets and further supports the representativeness of the SCQOL data for SSA migrants in Germany.

Country of origin variable from the SCQOL questionnaire was collapsed to form a new variable 'region of origin' to match data from the 2016 German foreign population report. The region West Africa, including Nigeria, Ghana, and Togo recorded the highest percentage followed by Eastern Africa, Central Africa, and last Southern Africa. Similar trends were reported in the GFPR 2016 where West Africa accounted for close to half of SSA migrants' population followed by Eastern Africa, Central Africa, and Southern Africa. Although East Africa has the highest regional population in African, the number of migrants from this region falls behind those from West Africa. This trend is believed to have resulted from West Africa high unemployment rates and 
relatively low wage rates, political instability and conflict and the prospect of economic, social and environmental stability as a means of improving their personal life in Europe and notably Germany (Afifi, 2011; Zimmermann, 1996).

The variation in data reported for the 16 German federal states of residence for SCQOL survey and GFPR 2016, is believed to have resulted from the adaptation of sampling technique. The systematic approach (wave 4) for data collection was more intensively applied in some states than others. For example, in Hamburg where 15.2\% of survey participants were drafted, more Afro stores; groups and associations, social and professional networks were contacted thereby increasing the chances of participation in this state. Increasing SCQOL sample size will, therefore, foster participation and facilitates a more similarly distributed state of residence data.

In general, the comparability of socio-demographic characteristics of SCQOL survey participant and data from the German foreign population report confirm the representativeness of the sample and the effectiveness of the 5-wave-approach sampling design as a valid method to approximate a random sample of Sub-Saharan African migrants in Germany. This approach, although very cumbersome, took into account the heterogeneity of many Sub-Saharan African culture, geographically dispensability of SSA migrant, network formation, and usage. The step by step approach makes this method a straightforward and adaptable tool to generate a representative sample from other hard to reach population.

\section{Limitations}

While this method succeeded in producing a sample that reflects population characteristics, the impracticality of recording participant per wave makes it hard to minimise oversampling of a particular network of peers or group. The influence of the researcher in recruiting study participant may also affect sample socioeconomic distribution. The waiting time for each wave makes the 5 -wave-approach time and resource consuming and not applicable in cases where quick results are needed.

\section{Implication for practices and research}

The 5-wave-approach presents a method capable of capturing a sample of SSA migrants that reflect population demographics characteristics. This development provides the very much needed entry point to solve the many problems faced by SSA migrants, bridging gaps in health and wellbeing. The practicability of this approach offers health and social worker, and SSA migrants' well-being interest groups with a communication channel that open up access to the larger group and facilitates the delivery of more efficient intervention project. Adapted from the Sudman \& Kalton sampling, this approach increases the chances of reaching every member of the hard-to-reach population group systematically, aids health promotion, and holistically facilitates community inclusion.

For researchers, the 5-waves-approach unravels a foundational challenge by providing access to acquiring a representative sample of SSA migrants from which in-depth knowledge of life and achievements can be investigated. Similarly, the representativeness of this approach further allows researchers to reach a generalisable conclusion that aids the development of more effective and efficient population oriented interventions towards reducing social and health inequalities and solving many other problems faced by members of these groups. Finally, this approach provides researchers with 
consolidated and holistic information that genuinely reflect population needs, features and characteristics of the hard-to-reach population.

\section{Abbreviations \\ SSA: Sub-Saharan African; SSA migrants: Sub-Saharan African migrants; GFPR: Germany foreign population report; SCQOLS: Social capital and quality of life survey}

\section{Acknowledgements}

I would like to express my gratitude to my supervisor, Prof. Monika Bullinger, for her ever present guidance and mentorship, patience and understanding. Thank you to the African community here in Germany for their corporation and to my wife, Elma and son; Elias, I am grateful for your energising love and encouragement.

\section{Funding}

No funding was received for this research project.

\section{Consent for publication}

Informed consent was obtained from all individual participants included in the study.

\section{Author's contributions}

The author read and approved the final manuscript.

\section{Ethics approval and consent to participate}

All procedures performed in studies involving human participants were in accordance with the ethical standards of the institutional and national research committee and with the 1964 Helsinki declaration and its later amendments or comparable ethical standards.

\section{Competing interests}

The author declares that he has no competing interests.

\section{Publisher's Note}

Springer Nature remains neutral with regard to jurisdictional claims in published maps and institutional affiliations.

Received: 26 December 2018 Accepted: 26 April 2019

Published online: 24 July 2019

\section{References}

Afifi, T. (2011). Economic or environmental migration? The push factors in Niger. International Migration, 49(s1), e95-e124. https://doi.org/10.1111/j.1468-2435.2010.00644.x.

Bonevski, B., Randell, M., Paul, C., Chapman, K., Twyman, L., Bryant, J., Hughes, C. (2014). Reaching the hard-to-reach: A systematic review of strategies for improving health and medical research with socially disadvantaged groups. BMC Medical Research Methodology, 14, 42. https://doi.org/10.1186/1471-2288-14-42.

Cohn, C. (2013). India and Nigeria: Similar colonial legacies, vastly different trajectories: An examination of the differing fates of two former British colonies. Cornell International Affairs Review, 7(1). Retrieved from http://www.inquiriesjournal.com/ articles/1483/india-and-nigeria-similar-colonial-legacies-vastly-different-trajectories-an-examination-of-the-differing-fatesof-two-former-british-colonies .

Deng, F. M. (1997). Ethnicity: An African predicament. Retrieved from https://www.brookings.edu/articles/ethnicity-an-africanpredicament/

Faugier, J., \& Sargeant, M. (1997). Sampling hard to reach populations. Journal of Advanced Nursing, 26(4), 790-797. https:// doi.org/10.1046/j.1365-2648.1997.00371.x.

Gabre-Madhin, E. Z., \& Haggblade, S. (2004). Successes in African agriculture. World Development, 32(5), 745-766. https://doi. org/10.1016/j.worlddev.2003.11.004

Grootaert, C., Narayan, D., Woolcock, M., \& Nyhan-Jones, V. (2004). Measuring social capital: an integrated questionnaire (no. 28110), (pp. 1-61) (World Bank Working Paper No. 18). Washington, DC: World Bank. Retrieved from http://documents. worldbank.org/curated/en/515261468740392133/Measuring-social-capital-an-integrated-questionnaire.

IOM (2013). World Migration Report 2013 - Migrant Well-being and Development, (Vol. 7). International Organization for Migration (IOM). Retrieved from https://publications.iom.int/books/world-migration-report-2013 .

Kalton, G. (2001, August 5-9). Practical Methods For Sampling Rare And Mobile Populations. Retrieved from http://www.asasrms. org/Proceedings/y2001/Proceed/00454.pdf.

Kang, H. (2013). The prevention and handling of the missing data. Korean Journal of Anesthesiology, 64(5), 402-406. https:// doi.org/10.4097/kjae.2013.64.5.402.

Ngubane, S. J. (2010). Gender roles in the African culture: Implications for the spread of HIV/aids, (p. 75). Stellenbosch: Stellenbosch University.

Palriwala and Uberoi. (2008). Marriage, migration and gender. New Delhi: SAGE Publications India Pvt Ltd. http://dx.doi.org/10. 4135/9788132100324. ISBN: 978-81-321-1186-3.

Patel, L., Kaseke, E., \& Midgley, J. (2012). Indigenous welfare and community-based social development: Lessons from African innovations. Journal of Community Practice, 20(1-2), 12-31. https://doi.org/10.1080/10705422.2012.644217.

Patel, L., Perold, H., Mohamed, S. E., \& Carapinha, R. (2007). Five-country study on service and volunteering in southern Africa, CSD Research Report 07-19 (). St. Louis: Washington University, Center for Social Development.

Petersen, L., Minkkinen, P., \& Esbensen, K. H. (2005). Representative sampling for reliable data analysis: Theory of sampling Chemometrics and Intelligent Laboratory Systems, 77(1), 261-277. https://doi.org/10.1016/j.chemolab.2004.09.013. 
Puchner, K., Karamagioli, E., Pikouli, A., Tsiamis, C., Kalogeropoulos, A., Kakalou, E., Pikoulis, E. (2018). Time to rethink refugee and migrant health in Europe: Moving from emergency response to integrated and individualized health care provision for migrants and refugees. International Journal of Environmental Research and Public Health, 15(6). https://doi.org/10. 3390/ijerph15061100.

Representative Sample (2008). In P. Lavrakas (Ed.), Encyclopedia of Survey Research Methods. Thousand Oaks: Sage Publications, Inc. https://doi.org/10.4135/9781412963947.n469.

Schapendonk, J. (2012). Turbulent trajectories: African migrants on their way to the European Union. Societies, 2(2), $27-41$. https://doi.org/10.3390/soc2020027.

Scott, P. (2004). Undocumented migrants in Germany and Britain: The human "rights" and "wrongs" regarding access to health care. Electronic Journal of Sociology. Retrieved from https://www.sociology.org/ejs-archives/2004/tier2/scott.html.

Skevington, S. M., Lotfy, M., O'Connell, K. A. (2004). The World Health Organization's WHOQOL-BREF quality of life assessment: Psychometric properties and results of the international field trial. A report from the WHOQOL group. Quality of Life Research, 13(2), 299-310. https://doi.org/10.1023/B:QURE.0000018486.91360.00 .

Statistisches Bundesamt (Destatis) (2017). Ausländische Bevölkerung - Ergebnisse des Ausländerzentralregisters 2016 [Foreign population - results of the Central Register of Foreigners 2016], (p. 489). Berlin: Statistisches Bundesamt (Destatis) (Ausländerzentralregisters). Retrieved from https://www.destatis.de/GPStatistik/receive/DEHeft_heft_00070063.

Sudman, S., \& Kalton, G. (1986). New developments in the sampling of special populations. Annual Review of Sociology, 12 401-429.

United Nations, Department of Economic and Social Affairs, Population Division (2015). World Population Prospects: The 2015 Revision, Key Findings and Advance Tables (Working Paper No. ESA/P/WP.241). Retrieved from https://population.un.org/ wpp/Publications/Files/Key_Findings_WPP_2015.pdf.

Weaver, D. A. (2000). The accuracy of survey-reported marital status: Evidence from survey records matched to social security records. Demography, 37(3), 395-399. https://doi.org/10.2307/2648050.

World Bank (2013). Jobs for shared prosperity: Time for action in the Middle East and North Africa, (p. 172). Washington, DC: World Bank.

Zimmermann, K. F. (1996). European migration: Push and pull. International Regional Science Review, 19(1-2), 95-128. https:// doi.org/10.1177/016001769601900211.

\section{Submit your manuscript to a SpringerOpen ${ }^{\circ}$ journal and benefit from:}

- Convenient online submission

- Rigorous peer review

- Open access: articles freely available online

- High visibility within the field

- Retaining the copyright to your article

Submit your next manuscript at $\boldsymbol{\nabla}$ springeropen.com 